\title{
The Community Dementia Reassurance Center (Chime Ansim Center) in South Korea
}

\author{
Seok Bum Lee \\ Department of Psychiatry, Dankook University Hospital, Cheonan, Korea
}

In 2018, the proportion of people aged over 65 years in South Korea exceeded 14\%, marking Korea's status as an aged society. ${ }^{1)}$ As the older population has increased, dementia care has become a major national issue. In 2017, the prevalence of patients with dementia was about 10.0\%, including an estimated 705,473 older people aged over 65 years. The number of patients with dementia is expected to exceed one million in 2024. The estimated annual cost for managing patients with dementia was 20.74 million won (Korean won) per person and over 14 trillion in total in 2017 (0.8\% of the gross domestic production). ${ }^{1)}$

Therefore, the Korean government has continuously established national policies for dementia care. In August 2008, the "War against Dementia" was announced, and the First National Dementia Plan (NDP-1) was made public by the Ministry of Health and Welfare of South Korea. The National Dementia Early Detection service and Medical Expense Support Program were initiated in January 2010 to encourage early diagnosis and delay the progression of dementia. $^{2)}$

The Dementia Management Act (DeMA) was legislated in August 2011. On the basis of DeMA, the National Institute of Dementia (NID) was established in May 2012 ${ }^{3)}$ and the NDP-2 was made public by the Ministry of Health and Welfare in July 2012. Moreover, Metropolitan/Provincial Dementia Centers (MDC/PDC) ${ }^{4,5)}$ were established successively from October 2013, and the National Dementia Helpline ${ }^{6)}$ started its counseling service in December 2013.

After preparations through the pilot (October-December 2014) and main research (May-November 2015) projects, the NDP-3 was made public by the Ministry of Health and Welfare in December 2015. ${ }^{2)}$ After winning the election in May 2017, President Moon Jae-in announced the National Duty for Dementia. ${ }^{7)}$ According to the National Duty for Dementia, Community Dementia Reassurance Centers (Chime Ansim Centers) were installed successively at all Community Health Centers (CHCs) to establish a community-based dementia management system. ${ }^{8)}$

The vision of the Chime Ansim Centers was as follows. First, patients with dementia should not experience difficulties in living in dementia-friendly communities.
Second, families should not experience difficulties in caring for patients with dementia. The three missions of the Chime Ansim Centers were as follows. First, acquisition of exact community data on dementia for appropriate management of dementia. Second, establishing and activating a Korean dementia care pathway. Third, improvement of dementia awareness by public education and volunteers (dementia partners). ${ }^{9)}$

The director of the CHCs was appointed as director of the Chime Ansim Centers. The Chime Ansim Centers include five teams for counseling/registration, early detection of dementia, daycare, family support, and dementia awareness/public information. The counseling/registration team provides counseling, registration of patients with dementia, intensive case management, and analysis of the achievements in dementia management. The dementia early detection team provides early detection program (screening, diagnosis, differential diagnosis) and intensive follow-up program for high-risk populations. The daycare team provides cognitive stimulation programs and support for affective and medical problems in patients with dementia. The family support team analyzes caregiver burdens and operates a cafe for patients with dementia and their families. The dementia awareness/public information team conducts programs to improve dementia awareness, train dementia partners, prevent dementia, and integrate community resources. ${ }^{8)}$

In conclusion, the Korean National Plan established a national dementia management system through the central (NID), metropolitan/provincial (MDC/PDC), and local (Chime Ansim Centers) governments. The Community Dementia Reassurance Centers (Chime Ansim Centers) will be the main service-providing organizations for community patients with dementia and their families.

\section{CONFLICTS OF INTEREST DISCLOSURES}

The author claims no conflicts of interest. 


\section{REFERENCES}

1. National Institute of Dementia. Korean Dementia observatory 2018 [Internet]. Seongnam: National Institue of Dementia; 2018 [cited 2018 Jun 25]. Available from: https://www.nid.or.kr/info/ dataroom_view.aspx?bid=194.

2. National Institute of Dementia. The 3rd National Dementia Plan [Internet]. Seongnam: National Institue of Dementia; 2015 [cited 2018 Jun 25]. Available from: https://www.nid.or.kr/info/dataroom_view.aspx?bid=144.

3. National Institute of Dementia [Internet]. Seongnam: National Institue of Dementia [cited 2018 Jun 25]. Available from: https:// www.nid.or.kr/main/main.aspx.

4. Seoul Metropolitan Dementia Center [Internet]. Seoul: Seoul Metropolitan Dementia Center [cited 2018 Jun 25]. Available from: https://seouldementia.or.kr/.

5. Chungnam Provincial Dementia Center [Internet]. Cheonan: Chungnam Provincial Dementia Center [cited 2018 Jun 25]. Available from: https://chungnam.nid.or.kr/home/main/main.aspx.

6. National Institute of Dementia. National Dementia Helpline [In- ternet]. Seongnam: National Institue of Dementia [cited 2018 Jun 25]. Available from: https://www.nid.or.kr/support/callcenter.aspx.

7. Gov't to take more responsibility for dementia patients. Yonhap News [Internet]. 2017 Jun 7 [cited 2018 Jun 25]. Available from: https://en.yna.co.kr/view/AEN20170607004000320.

8. Chime Ansim Center [Internet]. Seongnam: Chime Ansim Center [cited 2018 Jun 25]. Available from: https://ansim.nid.or.kr/main/ main.aspx.

9. Dementia Partner in Korea [Internet]. Seongnam: Dementia Partner in Korea [cited 2018 Jun 25]. Available from: https://partner. nid.or.kr/main/main.aspx.

Corresponding author Seok Bum Lee, MD, PhD Department of Psychiatry, Dankook University Hospital, 201 Manghyang-ro, Dongnam-gu, Cheonan 31116, Korea E-mail: bumlee@dankook.ac.kr

ORCID code: https://orcid.org/0000-0002-5481-4697

Received: June 25, 2019 Accepted: June 25, 2019 